\begin{abstract}
"Mircea cel Batran" Naval Academy Scientific Bulletin, Volume XX - 2017 - Issue 2
The journal is indexed in: PROQUEST / DOAJ / Crossref / EBSCOhost/ INDEX COPERNICUS/ OAJI / DRJI / JOURNAL INDEX / I2OR / SCIENCE LIBRARY INDEX / Google Scholar / Academic Keys / ROAD Open Access I Academic Resources / Scientific Indexing Services I SCIPIOI JIFACTOR
\end{abstract}

\title{
MARITIME ACCIDENTS OF TANKERS AND THEIR CONSEQUENCES
}

\author{
Alexandru Stefan BACIOIU ${ }^{1}$ \\ Alecu TOMA ${ }^{2}$ \\ ${ }^{1}$ MSc Student, Eng., „Mircea cel Batran” Naval Academy, Constanta, Romania, \\ bacioiu.alexandru@yahoo.com \\ ${ }^{2}$ Assistant Professor, Eng., PhD, „Mircea cel Batran” Naval Academy, Constanta, Romania, \\ alecu.toma@anmb.ro
}

\begin{abstract}
Despite the fact that more stringent regulations are coming into force in tanker industry, accidents are still happening and the worst consequences are coming out of this. The Master, owner, commercial operator, technical operator and all crew onboard have an obligation to comply with good and proper tanker practice. Human error can be seen everywhere but it is everyone's responsibility to understand that general safety practices should be applied at all times in order to avoid accidents. Many oil spills happened in the past decades and some of them are large or very large. The present article is presenting the history, practices and advices for avoiding maritime accidents and their consequences.
\end{abstract}

Keywords: maritime accidents, tankers, human factor, oil spill.

\section{INTRODUCTION}

Maritime transportation developed together with the global industrialization pushing the carriage of liquid cargoes using tankers to a new era by its economic advantages. The cost is directly influenced by the logistical efficiency through which the ships are exploited.

Neither shipowners nor charterers would reveal the true risks which hide behind the commercial pressure now widely present onboard vessels. It seems like the market of tankers went down in the past years which can be seen looking at time charterer rates of tankers all the way from Handy up to VLCC.

This forces the owners to cut the costs by all means using techniques like reducing the crew up to requirements stated in minimum safe manning certificate, hiring seafarers with little or even no experience on rank, buying or keeping in their fleet ships having a sub-standard level with the hope that another day will pass and no accident will happen.

Bringing together all these and many more, it is easy to identify that as we all know, the main cause of maritime accidents is human factor. Seafarers vary in many different ways, but industry should not forget that they are, nevertheless, people. The successes and the failures behind shipping are carried by humans with all the good and bad consequences which may come out of this.

In almost all shipping accidents the main cause is related to human element and having this in mind, trying to solve only technical problems onboard will cover just a small percent of the overall issues. To make a real change for the safety in all matters, higher attention should be made on human trainings in all aspects.

An accident can be seen as a series of events which are leading to bad consequences for people, environment, ship and cargo.

A near miss under different factors or circumstances could lead to an accident, but did not have any outcome and it should be seen as a lesson to be learned.

Shipping companies are taking accident prevention in a serious way because this can have a negative impact to the budget on short term but on the long term we are looking at the company competitiveness in terms of safety and reputation.

If an accident involving a tanker ship occurred, immediate action should be taken by all parties involved. Essential information should be included in the reporting of an oil spill like: details of person which is reporting the accident, name of tanker and owner, date and time of the accident, position, cause of the accident like collision, explosion, grounding, fire, description and quantity of bunker on board, cargo details, actions taken to combat oil spill, present status of vessel. accidents

Oil Spills as a consequence of Tanker

According to statistics, approximately 10,000 oil spills made by tankers were recorded, out of which $81 \%$ were less than 7 tonnes. The number of large oil spills recorded in the 70's compared to the oil spills recorded in the last years are considerably decreased from around 24.5 spills/year to only 1.7 spills/year. These figures are becoming better and better due to 
"Mircea cel Batran" Naval Academy Scientific Bulletin, Volume XX - 2017 - Issue 2

The journal is indexed in: PROQUEST / DOAJ / Crossref / EBSCOhost/ INDEX COPERNICUS/ OAJI / DRJI / JOURNAL INDEX / I2OR / SCIENCE LIBRARY INDEX / Google Scholar / Academic Keys / ROAD Open Access I Academic Resources I Scientific Indexing Services I SCIPIOI JIFACTOR

efforts made by shipping industry for improvement of safety and prevention of oil pollution.

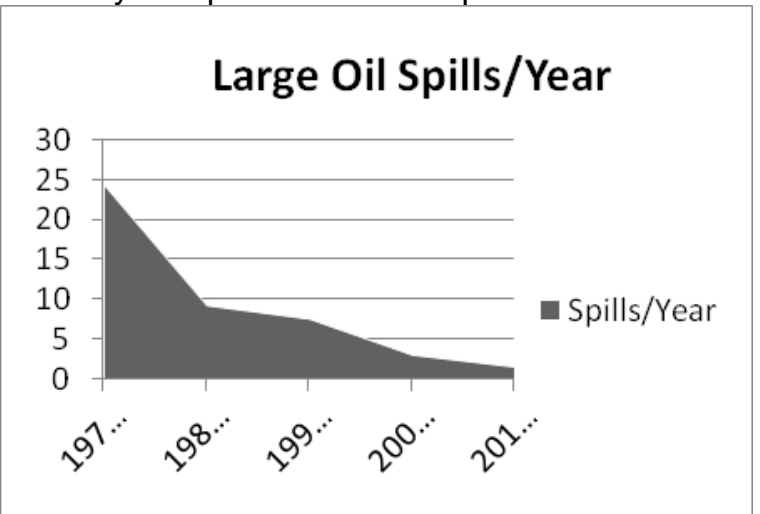

Figure 1. Large Oil Spills / Year from 70's to 2010's

Billions of dollars were paid by P\&l Clubs, Owners and Management Companies because of the massive pollution made by tankers and we can mention some of the biggest ever made:

- Atlantic Empress: 287,000 Tonnes;

- Castillo de Bellver: 252,000 Tonnes;

- $\quad$ Khark S: 70,000 Tonnes;

- Exxon Valdez: 37,000 Tonnes;

- $\quad$ Abt Summer: 260,000 Tonnes;

- Sea Empress: 72,000 Tonnes;

- Erika: 20,000 Tonnes;

- Prestige: 63,000 Tonnes;

- Hebei Spirit: 11,000 Tonnes.

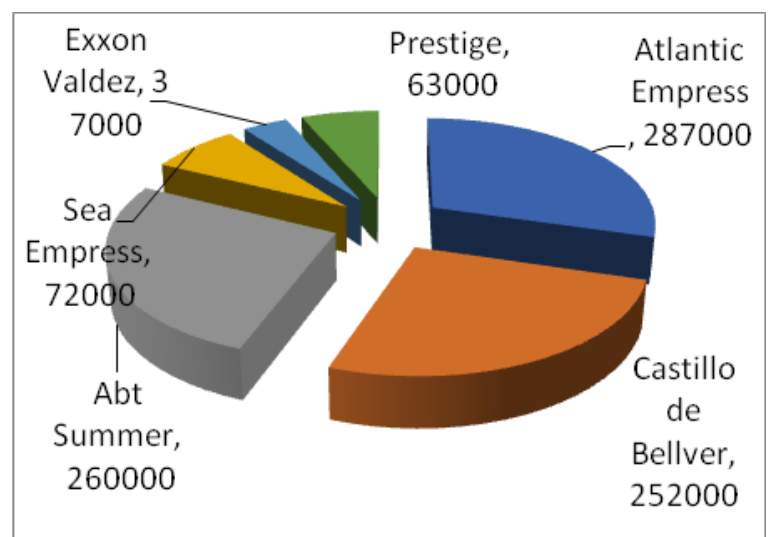

Figure 2.Some of the biggest oil spills ever made

Although world have seen an improvement regarding maritime pollution, efforts are continuously made and more stringent regulations are coming in force to reduce even more the accidents and all the consequences which come out of these.

Tankers while underway in open waters have around half of the total large oil spills and about $1 / 5$ while underway in coastal waters. The most important causes of accidents were and still are collisions and groundings with a total of almost 2/3.

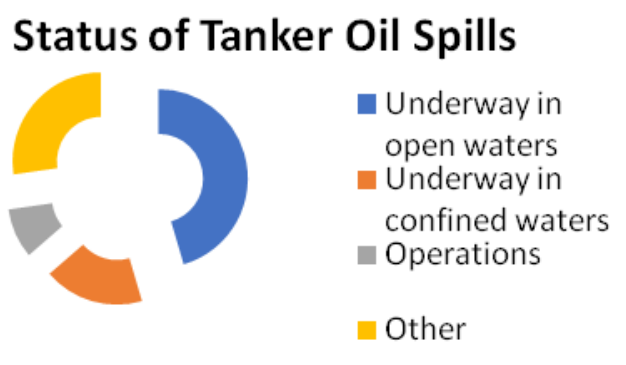

Figure 3. Tanker Oil Spills by status of vessel

One of the most important consequences from an accident involving tanker is oil spill. The oil is spreading on the surface of the sea and in the same time chemical and physical changes are happening.

Response to an oil spill can be made using different methods and plans:

- Booms and skimmers;

- In-situ burning;

- Dispersants;

- $\quad$ Protecting sensitive resources;

- Shore clean-up;

- Disposal.

Marine life can be seriously affected by maritime accidents of tankers not only temporary but also permanently. Marine resources are suffering sometimes an inevitable loss and this is a consequence of maritime accidents.

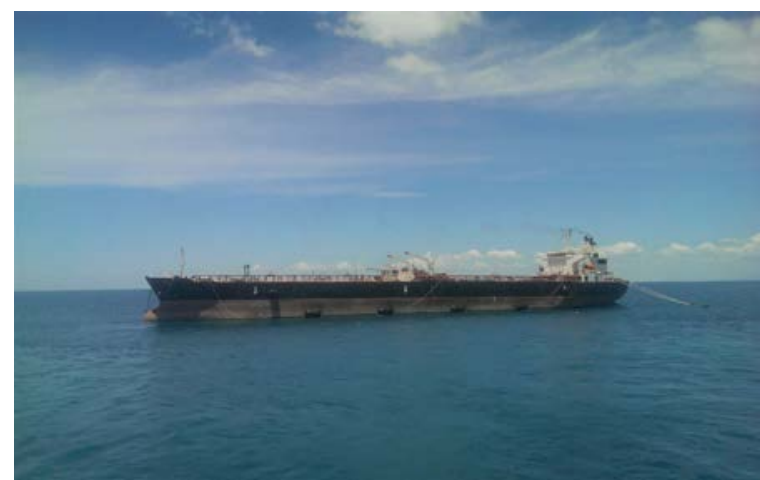

Figure 4. Tanker used for oil storage

There is a constant need in assessment of damage produced by spills regarding overall function of the marine ecosystem. The amount and type of oil, weather conditions, cleaning response, biological characteristics are part of the key in finding out the impact produced.

Immediate consequences of maritime accidents can be easily seen, but also long term damage should be taken into account. The economic impact is serious and is affecting also tourism in the area where the spill made its victims.

Seawater is an important resource also for the industries that rely on it and oil spill and 
"Mircea cel Batran" Naval Academy Scientific Bulletin, Volume XX - 2017 - Issue 2

The journal is indexed in: PROQUEST / DOAJ / Crossref / EBSCOhost/ INDEX COPERNICUS/ OAJI / DRJI / JOURNAL INDEX / I2OR / SCIENCE LIBRARY INDEX / Google Scholar / Academic Keys / ROAD Open Access I Academic Resources / Scientific Indexing Services / SCIPIOI JIFACTOR

cleaning process will definitely affect them. Normal operations of ports, terminals and shipyards will most probably be interrupted.

Marine environment although suffered from the impact of oil spills, recovered in most of the cases within a relatively short period of time.

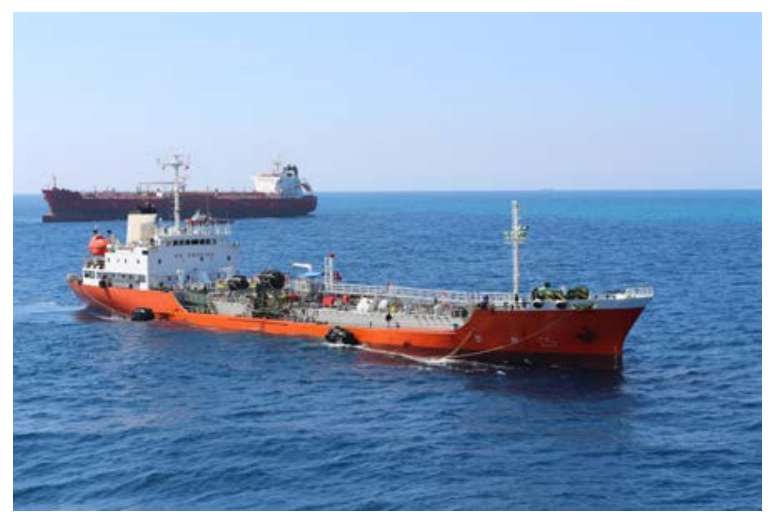

Figure 5. Tanker used for bunkering

Maritime accidents of tankers can be categorized into following:

- Collision;

- Grounding;

- Fire;

- Breakaway during cargo operations;

- Hose burst;

- Hazardous vapor release;

- Hull failure;

- Hull leak;

- Flooding;

- Sinking:

- Main engine failure;

- $\quad$ Steering failure.
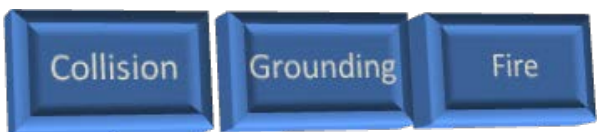

Hull failure
Figure6. Maritime accidents by category

Following information are includedin the report depending on the maritime accident category:

- Type of incident;

- Local time and date;

- Exact position of incident;

-Estimated extent of damage to own ship;

-Details of injuries or deaths; damaged;

-Amount of cargo and bunkers lost or

-Precautions already taken;

Other information which should be included in the initial report:

In case of collision:

- Information about other ship;

- Damages on other ship;

In case of grounding:

- Draft before and after incident;

- Soundings around the vessel;

In case of Fire:

- Status of flammable, toxic or explosive cargo onboard;

- What methods of fire-fighting are available;

- $\quad$ Present status of situation;

Regarding other incidents it is very important to recognize the potential dangers which may rise. In case of main engine failure and/or Steering failure if the tanker is in confined waters, fairways, port limits it can easily become a collision or grounding situation. All incidents should be treated seriously and response matrix to be followed by the team onboard. Permanent contact with office, authorities and other third party should happen. 
"Mircea cel Batran" Naval Academy Scientific Bulletin, Volume XX - 2017 - Issue 2 The journal is indexed in: PROQUEST / DOAJ / Crossref / EBSCOhost/ INDEX COPERNICUS/ OAJI / DRJI / JOURNAL INDEX / I2OR / SCIENCE LIBRARY INDEX / Google Scholar / Academic Keys / ROAD Open Access I Academic Resources / Scientific Indexing Services I SCIPIOI JIFACTOR

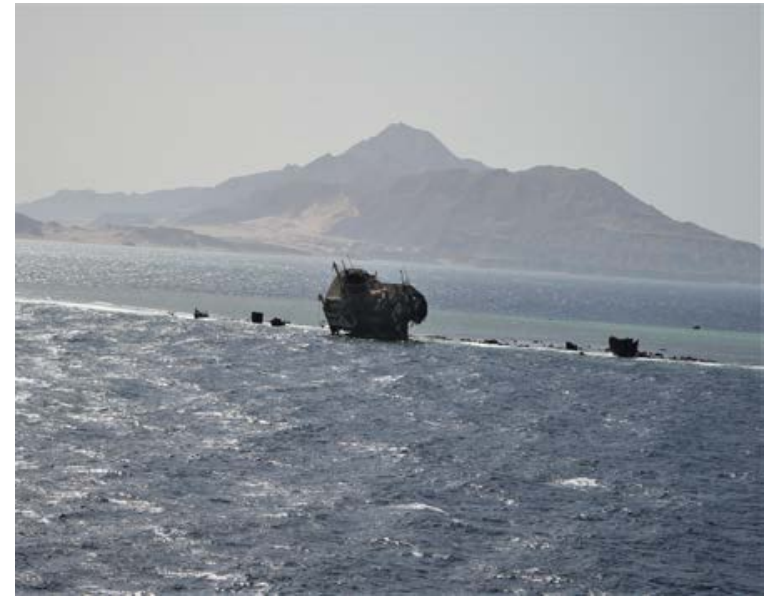

Figure 7. Wreck of a ship

Emergency Muster Plan will identify teams and team leaders as follows:

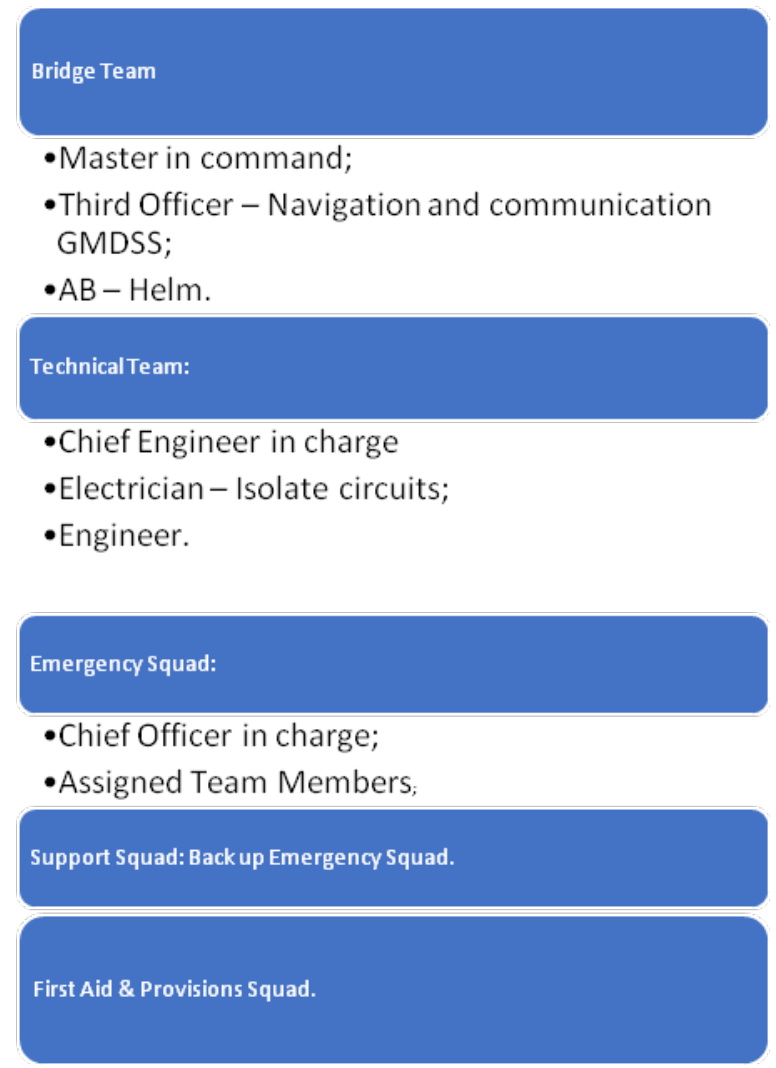

Figure 8. Emergency Plan with Teams

\section{CONCLUSIONS}

Companies should be committed to prove that safe working conditions onboard ships are the main priority when it comes to safety environment. With a well implemented safety culture, seafarers will think twice before making a move which can lead to serious consequences regarding people, ship, cargo and environment.

Leadership, trust, teamwork are not just some words, are a link between compliance management and safety culture. Both teams from ship and shore have a key importance when it comes to prevent maritime accidents and their consequences. Having all this in mind, we are looking at a safe future. 
"Mircea cel Batran" Naval Academy Scientific Bulletin, Volume XX - 2017 - Issue 2 The journal is indexed in: PROQUEST / DOAJ / Crossref / EBSCOhost/ INDEX COPERNICUS/ OAJI / DRJI / JOURNAL INDEX I I2OR / SCIENCE LIBRARY INDEX / Google Scholar / Academic Keys I ROAD Open Access I Academic Resources I Scientific Indexing Services I SCIPIOI JIFACTOR

\section{BIBLIOGRAPHY:}

[1] IMO, Manual on oil pollution Section I - Prevention, London, 2011

[2]IMO, Manual on oil pollution Section II - Contingency Planning, London, 1995

[3]IMO, Manual on oil pollution Section IV - Combating Oil Spills, London, 2005

[4]ITOPF, Handbook, London, 2017

[5]IMO, Shipboard marine pollution emergency plans, London, 2010

[6]The Nautical Institute, Guidelines for collecting maritime evidence, London, 2017

[7]Witherby, Chemical Tankers A pocket Safety Guide, Edinburgh, 2013 